\title{
Brain volume in first-episode schizophrenia
}

\author{
Systematic review and meta-analysis of magnetic resonance \\ imaging studies
}

\section{R. GRANT STEEN, COURTNEY MULL, ROBERT MCCLURE, ROBERT M. HAMER and JEFFREY A. LIEBERMAN}

\begin{abstract}
Background Studies of people with schizophrenia assessed using magnetic resonance imaging (MRI) usually include patients with first-episode and chronic disease, yet brain abnormalities may be limited to those with chronic schizophrenia.
\end{abstract}

\begin{abstract}
Aims To determine whether patients with a first episode of schizophrenia have characteristic brain abnormalities.
\end{abstract}

\begin{abstract}
Method Systematic review and metaanalysis of 66 papers comparing brain volume in patients with a first psychotic episode with volume in healthy controls.
\end{abstract}

Results A total of 52 cross-sectional studies included 1424 patients with a first psychotic episode; 16 longitudinal studies included 465 such patients. Meta-analysis suggests that whole brain and hippocampal volume are reduced (both $P<0.000 \mathrm{I})$ and that ventricular volume is increased $(P<0.000 \mathrm{I})$ in these patients relative to healthy controls.

\section{Conclusions Average volumetric changes are close to the limit of detection by $M R I$ methods. It remains to be determined whether schizophrenia is a neurodegenerative process that begins at about the time of symptom onset, or whether it is better characterised as a neurodevelopmental process that produces abnormal brain volumes at an early age.}

\section{Declaration of interest None.}

Schizophrenia is a disabling illness that affects over 2 million people in the USA alone, but its aetiology remains poorly understood (Harrison, 1999; Siever \& Davis, 2004). In past years the disorder was studied by examining pathological brain tissue samples, often derived from patients who had died after a prolonged period of illness. In recent years, with the advent of brain imaging methods such as magnetic resonance imaging (MRI), it has become possible to study patients during their first episode of psychosis, before disease effects are obscured by the confounding influences typical of cases of chronic schizophrenia. This may make it possible to test hypotheses as to which brain volumetric changes are primary to the development of schizophrenia (Shenton et al, 2001). Our goal in the study reported here is to provide an update of two excellent earlier reviews (Wright et al, 2000; Shenton et al, 2001), but with a focus specifically on patients with first-episode schizophrenia.

\section{METHOD}

\section{Study selection criteria}

Relevant studies of patients with firstepisode schizophrenia were identified in multiple searches as late as November 2004. The primary search used PubMed and the keywords SCHIZOPHRENIA and FIRST-EPISODE and MAGNETIC RESONANCE IMAGING and VOLUME, in all possible combinations. This search was repeated, substituting the keyword DRUG NAIVE for FIRST-EPISODE, and using the same search words again in all possible combinations. A secondary search was then undertaken, using each primary reference as a source. The bibliography of each source was searched for additional references that were missed by the PubMed search. In addition, the bibliographies of eight key review articles were searched (Wright et al, 2000; Konick \& Friedman, 2001; Okubo et al, 2001; Shenton et al,
2001; Kasai et al, 2002; Torrey, 2002; Davidson \& Heinrichs, 2003; Antonova et $a l, 2004)$ for papers relating specifically to patients with first-episode disorder. Finally, current journals were reviewed to find references too new to have been reviewed. The primary search found 75 relevant references, whereas the secondary searches found an additional 16 references.

Studies were included in our analysis if brain MRI volumetric data were reported for both a population of patients with schizophrenia at first episode and a population of healthy controls evaluated concurrently. We excluded seven studies that did not report exclusively on patients with first-episode illness, and five studies that did not report concurrent data from healthy controls. Studies were also excluded if data from patients with first-episode psychosis were not separated from a larger population of patients with psychosis of some other type, or if results included patients with childhood-onset schizophrenia. We specifically excluded children younger than age 13 years from our analysis because there are rapid changes in brain volume among healthy children up to about age 9 years (Pfefferbaum et al, 1994; Giedd et $a l, 1999$ ), and the young age of patients with childhood-onset illness would make it difficult to control adequately for the effects of normal brain growth. Studies were also excluded if data were reported in a format that did not enable us to calculate patient brain volume as a percentage of the control group volume. Thus, we excluded studies that used voxel-based morphometry, since our calculations are based on volume rather than on number of pixels. We also excluded studies that reported results from a non-volumetric analysis of the data, or from a non-quantitative analysis of the data.

Of the total of 91 articles that were originally identified, 26 were excluded for any of the above reasons. A total of 65 articles were evaluated (Table 1), including 52 cross-sectional and 16 longitudinal studies. Data from all 52 eligible crosssectional studies were entered into a spreadsheet that tabulated study details, including a brief description of the study, demography of the study populations, patient medications and the statistical analyses used. For patients, additional data were entered summarising the percentage difference in structure volume relative to controls, and whether or not this difference was statistically significant according to the analysis presented in the original reference. 
The data entry process was then repeated for all eligible longitudinal studies. If a longitudinal study reported baseline data in a format that could be analysed as a cross-sectional study, this study was entered into both the cross-sectional and the longitudinal databases. The final database contained approximately 29084 cells.

\section{Data analysis}

We sorted the cross-sectional database by brain structure, to determine where brain volumetric changes had been sought. Brain volume changes in the first-episode group were summarised, with respect to controls, on a structure-by-structure basis (further information available from the author upon request). We then conducted a meta-analysis of all cross-sectional studies that measured whole-brain volume in the first-episode group relative to controls (Table 2). For each component study in the metaanalysis, we abstracted information about sample properties (size, mean and standard deviation) from the original paper and fitted a blocked analysis of variance model (with study as the blocking factor) to examine group differences. We additionally fitted models with the group $\times$ treatment interaction, to assess heterogeneity; interactions were non-significant in all cases, so we used the models without the interaction terms. We did similar metaanalyses of cross-sectional studies that measured differences in hippocampal volume (Table 3) and ventricular volume (Table 4). Finally, we summarised all studies that reported longitudinal volumetric changes significant at $P \leqslant 0.01$ (further information available from the author upon request), to address the issue of which longitudinal changes are most robust by statistical criteria.

\section{RESULTS}

The primary PubMed search was able to find 75 of the 91 papers evaluated in this study, or $82 \%$ of the relevant references. This suggests that PubMed, although an effective tool, cannot be relied upon to find all relevant references.

A total of 52 studies were included in the cross-sectional analysis (Table 1), these studies involving 1424 patients with firstepisode schizophrenia (30.3 patients per study, s.d. $=16.5)$ and 1315 healthy controls (28.0 controls per study, s.d. $=10.7)$. A total of 16 studies were included in the longitudinal analysis, these studies involving 465 patients (33.2 patients per study,
Table I Summary of cross-sectional and longitudinal studies included in review

\begin{tabular}{|c|c|c|c|c|}
\hline \multirow[t]{2}{*}{ Study } & \multicolumn{2}{|c|}{ Sample size } & \multirow{2}{*}{$\begin{array}{l}\text { Patient age } \\
\text { Mean (years) }\end{array}$} & \multirow{2}{*}{$\begin{array}{c}\text { Male } \\
\%\end{array}$} \\
\hline & $\begin{array}{c}\text { Patient group } \\
n\end{array}$ & $\begin{array}{c}\text { Control group } \\
n\end{array}$ & & \\
\hline
\end{tabular}

\section{Cross-sectional studies}

\section{Bachmann et al (2003)}

Barr et al (1997)

Bilder et al (1994)

Bogerts et al (1990)

Cahn et al (2002a)

Chua et al (2003)

Corson et al (1999)

Crespo-Facorro et al (2000)

Degreef et al (1992)

DeLisi et al (199I)

DeLisi et al (1992)

DeLisi et al (1994)

Ettinger et al (200 I)

Fannon et al (2000a)

Fannon et al (2000b)

Gilbert et al (200 I)

Gunduz et al (2002)

Hirayasu et al (1998)

Hirayasu et al (1999)

Hirayasu et al (2000b)

Hirayasu et al (200 I)

Hoff et al (1994)

James et al (1999)

Joyal et al (2002)

Joyal et al (2003)

Kasai et al (2003a)

Keshavan et al (1998a)

Keshavan et al (1998b)

Laakso et al (200 I)

Lang et al (200 I)

Lawrie et al (1999)

Lee et al (2002)

Lim et al (1996)

Matsumoto et al (200 la)

McCarley et al (2002)

Niemann et al (2000)

Nopoulos et al (1995)

Razi et al (1999)

Salokangas et al (2002)

Smith et al (2003)

Sumich et al (2002)

Szeszko et al (1999)

Szeszko et al (2003a)

Szeszko et al (2003b)

Velakoulis et al (1999)

\section{2}

42

51

25

20

29

41

25

25

20

33

40

29

25

25

25

28

18

20

22

17

35

20

22

22

29

17

17

22

23

30

24

51

40

18

20

24

31

19

19

16

26

49

34

42
$26.4 \quad 45$

$26.3 \quad 59$

$26.1 \quad 56$

$25 \quad 63$

$27.6 \quad 80$

$31.6 \quad 90$

$26.9 \quad 69$

25.4 NR

24.I 63

$27.3 \quad 77$

$26.2 \quad 64$

$26.9 \quad 59$

24.274

$24 \quad 71$

$24.3 \quad 70$

$26.6 \quad 69$

$24.5 \quad 73$

$26.7 \quad 82$

$27.2 \quad 82$

$27.3 \quad 80$

$22.8 \quad 88$

$26.5 \quad 63$

$16.8 \quad 69$

$28 \quad 61$

$28 \quad 61$

$25.2 \quad 85$

$27.2 \quad 69$

25.47

$28 \quad 6$

$22.9 \quad 70$

$20.7 \quad 75$

$26 \quad 77$

$25.2 \quad 68$

$15.5 \quad 50$

$27.6 \quad 80$

$27.4 \quad 100$

$23.3 \quad 50$

$23.4 \quad 54$

$36.6 \quad 27$

$22.8 \quad 79$

$24 \quad 100$

$26 \quad 53$

27.I 54

$25 \quad 67$

$20.8 \quad 88$

(continued overleaf) 
Table I (continued)

\begin{tabular}{|c|c|c|c|c|}
\hline \multirow[t]{2}{*}{ Study } & \multicolumn{2}{|c|}{ Sample size } & \multirow{2}{*}{$\begin{array}{l}\text { Patient age } \\
\text { Mean (years) }\end{array}$} & \multirow{2}{*}{$\begin{array}{c}\text { Male } \\
\%\end{array}$} \\
\hline & $\begin{array}{c}\text { Patient group } \\
n\end{array}$ & $\begin{array}{c}\text { Control group } \\
n\end{array}$ & & \\
\hline Whitworth et al (1998) & 41 & 32 & 24.5 & 100 \\
\hline Zipursky et al (I998a) & 46 & 61 & 26.2 & 54 \\
\hline Total & 1424 & 1315 & & \\
\hline Mean (s.d.) & $30.3(16.5)$ & $28.0(10.7)$ & $25.5(3.2)$ & 67.4 \\
\hline
\end{tabular}

Studies reporting new data supplementing cross-sectional studies above

Hirayasu et al (2000a) describes data from Hirayasu et al (1998)

Copolov et al (2000) describes data from Velakoulis et al (1999)

Zipursky et al (1998b) describes data from Zipursky et al (1998a)

Lieberman et al (1992) describes data from Bogerts et al (1990), Degreef et al (1992)

Matsumoto et al (200 lb) describes data from Matsumoto et al (200 la)

Longitudinal studies
Cahn et al (2002b)
Chakos et al (1994)
Degreef et al (199I)
DeLisi et al (1992)
DeLisi et al (1995)
DeLisi et al (1997)
Gur et al (1998)
Ho et al (2003)
Kasai et al (2003b)
Keshavan et al (1998b)
Lang et al (200 I)
Lieberman et al (200 I)
Puri et al (200 I)
Wood et al (200 I)
Total
Mean (s.d.)

Studies reporting new data supplementing longitudinal studies above

DeLisi et al (1998) describes data from DeLisi et al (1997)

Kasai et al (2003c) describes data from Kasai et al (2003b) are significant relate to grey matter, and more findings relate to central than to peripheral (cortical) grey matter. Virtually all significant volumetric differences from normal in grey matter are patient deficits in volume, compared with controls.

Cross-sectional studies that measured whole-brain volume deficits in patients with first-episode schizophrenia are summarised in Table 2. For this particular comparison there have been 21 studies, with a large number of participants (patients, $n=524$; controls, $n=650$ ), but only 4 studies found significance. Meta-analysis showed that the average patient brain volume was $2.7 \%$ smaller than the average control brain volume $(P<0.0001)$. Group (patient $v$. control) and study differences together account for $57 \%$ of the variation in brain volume, but group differences alone were able to account for less than $1 \%$ of the variation in brain volume $(P<0.0001)$. Thus, there was a significant variation in brain volume between studies $(P<0.0001)$, although there was no significant study heterogeneity.

There was variation in the number (and type) of covariates used in the various studies of brain volume, suggesting that it may be problematic to pool studies in a single meta-analysis. Nevertheless, the number of statistical covariates used in analysis did not seem to be related to the level of statistical significance obtained. The 4 studies that found significance had an average of 2.0 covariates, whereas the 17 non-significant studies had an average of 2.2 covariates.

Cross-sectional studies that measured hippocampal volume deficits in patients with first-episode schizophrenia are summarised in Table 3. There have been 10 separate studies of the hippocampus, with total participant numbers of 300 patients and 287 controls. Meta-analysis shows that the volume deficit in patient hippocampus is about $8 \%$ on both right and left sides $(P<0.0001)$. This deficit is somewhat larger than the $4 \%$ volume deficit reported in a meta-analysis of hippocampal volume in patients with chronic schizophrenia (Nelson et al, 1998). Group and study differences together accounted for $64 \%$ of the variation in hippocampal volume, but group differences alone were able to account for only $2 \%$ of this variation $(P<0.0001)$. Study-related variation in hippocampal volume was significant $(P<0.0001)$, without significant study heterogeneity. 
Table 2 Whole-brain volume in cross-sectional studies

\begin{tabular}{|c|c|c|c|c|c|c|c|c|c|}
\hline \multirow[t]{3}{*}{ Reference } & \multicolumn{6}{|c|}{ Whole-brain volume, $\mathrm{cm}^{3}$} & \multirow{3}{*}{$\begin{array}{c}\text { Patient volume' } \\
\%\end{array}$} & \multirow[t]{3}{*}{ Covariates } & \multirow[t]{3}{*}{$P$} \\
\hline & \multicolumn{3}{|c|}{ Patient group } & \multicolumn{3}{|c|}{ Control group } & & & \\
\hline & Mean & (s.d.) & $n$ & Mean & (s.d.) & $\mathrm{n}$ & & & \\
\hline Cahn et al (2002a) & 1281.6 & (II8.7) & 20 & 1353.9 & (139) & 20 & 94.7 & 1 & NS \\
\hline Lee et al (2002) & 1499.2 & $(120.2)$ & 22 & 1555.2 & (149.9) & 24 & 96.4 & 2 & NS \\
\hline Hirayasu et al (200 I) & 1513 & (II7) & 17 & 1469 & (154) & 17 & 103.0 & 1 & NS \\
\hline Fannon et al $(2000 a)$ & 991.1 & $(76.0)$ & 21 & 1075.8 & $(113.0)$ & 25 & 92.1 & 3 & $<0.02$ \\
\hline Fannon et al (2000b) & 1015.3 & $(98.5)$ & 37 & 1075.8 & $(113.0)$ & 25 & 94.4 & 3 & $<0.05$ \\
\hline James et al (1999) & 1383 & $(163)$ & 29 & 1405 & (170) & 20 & 98.4 & 2 & NS \\
\hline Hirayasu et al (1999) & 1510 & $(10 \mathrm{I})$ & 17 & 1533 & (166) & 20 & 98.5 & 2 & NS \\
\hline Szeszko et al (1999): Men & 1347 & $(105)$ & 10 & 1368 & (97) & 16 & 98.5 & 3 & NS \\
\hline Szeszko et al (1999): Women & 1173 & $(8 I)$ & 9 & 1231 & (III) & 10 & 95.3 & 3 & NS \\
\hline Velakoulis et al (1999) & 1341.8 & $(134.9)$ & 16 & I372.I & $(144.4)$ & 140 & 97.8 & 5 & NS \\
\hline Lawrie et al (1999) & 1356 & (178) & 20 & 1334 & (149) & 30 & 101.6 & 1 & NS \\
\hline Keshavan et al (1998b) & 1470.0 & $(183.0)$ & 17 & 1578.9 & $(160.3)$ & 17 & 93.1 & 1 & $<0.05$ \\
\hline Whitworth et al (1998) & 1210.2 & $(119.2)$ & 41 & 1246.7 & $(84.2)$ & 32 & 97.1 & 2 & NS \\
\hline Zipursky et al (1998a) & 1087 & (II4) & 46 & 1108 & $(132)$ & 61 & 98.1 & 2 & NS \\
\hline Nopoulos et al (1995) & 1240 & (139) & 24 & 1270 & (133) & 24 & 97.6 & 2 & NS \\
\hline DeLisi et al (1991) & 1199.8 & $(139.3)$ & 30 & 1204.7 & $(138.3)$ & 20 & 99.6 & 4 & NS \\
\hline Kasai et al (2003a) & 1469 & (II4) & 27 & 1510 & $(162)$ & 29 & 97.3 & 2 & NS \\
\hline Szeszko et al (2003b) & 1459 & $(168)$ & 46 & 1476 & (128) & 34 & 98.8 & 4 & NS \\
\hline Chua et al (2003) & 1392.1 & $(156.9)$ & 19 & 1408.7 & (98.4) & 29 & 98.8 & 1 & NS \\
\hline Matsumoto et al (200 la) & 1254.0 & $(I 17.2)$ & 40 & 1320.0 & $(123.4)$ & 40 & 95.0 & 1 & 0.002 \\
\hline Keshavan et al (1998a) & 1477.0 & $(\mid 85.3)$ & 16 & 1576.6 & $(173.0)$ & 17 & 93.7 & 0 & NS \\
\hline Meta-analysis & 1318.1 & & 524 & 1354.7 & & 650 & 97.3 & & $<0.0001$ \\
\hline
\end{tabular}

I. Volume expressed as a percentage of control brain volume.

Cross-sectional studies that measured the lateral or third ventricles in patients with first-episode schizophrenia are also summarised (Table 4). There have been 11 studies of ventricular volume, with total participant numbers of 204 patients and 209 controls. Meta-analysis shows that the lateral ventricle volume surplus in patients is about $34 \%$ on the left side and $25 \%$ on the right side (both $P<0.0001$ ). Group and study differences together account for $31 \%$ of the variation in ventricular volume on the left side and $26 \%$ on the right side (both $P<0.0001$ ), with group differences accounting for $6 \%$ or less of the variation in ventricular volume (both $P<0.0001$ ). For third ventricle measurements, group and study differences together accounted for $68 \%$ of the variation in third ventricle volume $(P<0.0001)$, with group differences accounting for $4 \%$ of the variation in ventricular volume. Study-related variation in ventricular volume was significant (all $P<0.0001$ ), without significant study heterogeneity.
We summarised robustly significant $(P \leqslant 0.01)$ findings from longitudinal studies of brain volume change in patients (further information available from the author upon request). This compilation demonstrates that longitudinal studies are generally of recent vintage; of eight studies recorded, five were published within the past 5 years. Several longitudinal changes in the volume of the brain were robustly significant after diagnosis, including a significant decrease in volume of the whole brain after diagnosis. No significant longitudinal change was identified in white matter or cerebellum, so longitudinal changes in whole-brain volume may be limited to the grey matter.

\section{DISCUSSION}

Our synthesis of brain volumetric studies suggests that a great deal more work is needed. There are relatively few studies that specifically relate to patients with first episodes of schizophrenia (see Table 1); the existing studies have a rather small sample size and studies that reported a high degree of significance tended to have a smaller sample size than normal. Most significant volumetric findings are not well replicated, and few findings are robustly significant, in either cross-sectional or longitudinal studies. Studies of patients with first episodes tend to be smaller than the average of 33 patients per study reported in a systematic review of 180 studies of patients with (mostly) chronic schizophrenia (Shenton et al, 2001). Thus, the total number of first-episode cases that have been evaluated overall is small, given the complexity of the illness.

\section{Whole-brain volume deficits}

Whole-brain volume differences between first-episode cases and controls are apparently quite subtle (Harrison et al, 2003). Cross-sectional studies that measured whole-brain volume reported an average volume deficit in the first-episode group of less than $3 \%$ (see Table 2), despite a large 
Table 3 Hippocampal volume in cross-sectional studies

\begin{tabular}{|c|c|c|c|c|c|c|c|c|}
\hline \multirow[t]{3}{*}{ Reference' } & \multicolumn{6}{|c|}{ Hippocampal volume, $\mathrm{mm}^{3}$} & \multirow{3}{*}{$\begin{array}{c}\text { Patient volume } \\
\%\end{array}$} & \multirow[t]{3}{*}{$P$} \\
\hline & \multicolumn{3}{|c|}{ Patient group } & \multicolumn{3}{|c|}{ Control group } & & \\
\hline & Mean & (s.d.) & $n$ & Mean & (s.d.) & $n$ & & \\
\hline \multicolumn{9}{|l|}{ Left } \\
\hline Smith et al (2003): Men & 3.01 & $(0.42)$ & 26 & 3.13 & $(0.36)$ & 10 & 96.2 & NS \\
\hline Smith et al (2003): Women & 2.68 & $(0.18)$ & 7 & 2.92 & $(0.31)$ & 9 & 91.8 & NS \\
\hline Sumich et al (2002) & 2.70 & $(0.30)$ & 25 & 3.08 & $(0.25)$ & 16 & 87.7 & 0.007 \\
\hline Laakso et al (200 I) & 1.21 & $(0.24)$ & 18 & 1.23 & $(0.18)$ & 22 & 98.4 & NS \\
\hline Niemann et al (2000) & 1.85 & $(0.32)$ & 20 & 1.88 & $(0.25)$ & 20 & 98.4 & NS \\
\hline James et al (1999) & 2.35 & $(0.47)$ & 29 & 2.52 & $(0.5 I)$ & 20 & 93.3 & NS \\
\hline Velakoulis et al (1999) & 2.71 & $(0.52)$ & 16 & 3.05 & $(0.37)$ & 42 & 88.9 & 0.02 \\
\hline Whitworth et al (1998) & 2.45 & $(0.38)$ & 41 & 2.82 & $(0.5 I)$ & 32 & 86.9 & $<0.01$ \\
\hline Barr et al (1997) & 2.42 & $(0.47)$ & 32 & 2.55 & $(0.44)$ & 42 & 94.9 & $<0.001$ \\
\hline Szeszko et al (2003b) & 3.31 & $(0.4 I)$ & 46 & 3.56 & $(0.43)$ & 34 & 93.0 & $<0.01$ \\
\hline Matsumoto et al (200 la) & 2.45 & $(0.49)$ & 40 & 2.69 & $(0.50)$ & 40 & 91.1 & NS \\
\hline Meta-analysis & 2.46 & & 300 & 2.68 & & 287 & 91.8 & $<0.0001$ \\
\hline \multicolumn{9}{|l|}{ Right } \\
\hline Smith et al (2003): Men & 3.00 & $(0.47)$ & 26 & 3.19 & $(0.36)$ & 10 & 94.0 & NS \\
\hline Smith et al (2003): Women & 2.86 & $(0.39)$ & 7 & 3.01 & $(0.33)$ & 9 & 95.0 & NS \\
\hline Sumich et al (2002) & 2.74 & $(0.38)$ & 25 & 3.17 & $(0.29)$ & 16 & 86.4 & 0.02 \\
\hline Laakso et al (200 I) & 1.22 & $(0.23)$ & 18 & 1.27 & $(0.19)$ & 22 & 96.1 & NS \\
\hline Niemann et al (2000) & 2.01 & $(0.27)$ & 20 & 2.10 & $(0.34)$ & 20 & 95.7 & NS \\
\hline James et al (1999) & 2.40 & $(0.45)$ & 29 & 2.44 & $(0.43)$ & 20 & 98.4 & NS \\
\hline Velakoulis et al (1999) & 2.94 & $(0.39)$ & 16 & 3.22 & $(0.40)$ & 42 & 91.3 & NS \\
\hline Whitworth et al (1998) & 2.42 & $(0.35)$ & 41 & 2.75 & $(0.66)$ & 32 & 88.0 & $<0.01$ \\
\hline Barr et al (1997) & 2.21 & $(0.40)$ & 32 & 2.71 & $(0.47)$ & 42 & 81.5 & NS \\
\hline Szeszko et al (2003b) & 3.41 & $(0.43)$ & 46 & 3.61 & $(0.43)$ & 34 & 94.5 & NS \\
\hline Matsumoto et al (200 la) & 2.70 & $(0.42)$ & 40 & 2.80 & $(0.51)$ & 40 & 96.4 & NS \\
\hline Meta-analysis & 2.53 & & 300 & 2.76 & & 287 & 91.7 & $<0.000 \mathrm{I}$ \\
\hline
\end{tabular}

I. Cahn et al (2002a) is not included in this evaluation because it did not report left and right hippocampal volume separately.

2. Volume expressed as a percentage of control hippocampal volume.

sample size. This finding agrees well with a study of brain weight at autopsy, in which 540 older patients with chronic schizophrenia were compared with 794 controls (Harrison et al, 2003). This study found that the brain weight of patients with chronic disorder was $2 \%$ less than that of healthy controls $(P=0.04)$, but that disease-related differences were far less significant than brain weight differences attributable to either age or gender (both $P<0.0001)$. No correlation was found between brain weight and the duration of psychosis, which may mean that brain atrophy is not progressive after diagnosis (Harrison et al, 2003).

It is critically important to determine when whole-brain volume deficits in patients with schizophrenia first become significant, as this could have bearing on the aetiology of the disorder (Harrison, 1999). If whole-brain volume becomes abnormal early in childhood, this would suggest a neurodevelopmental aetiology; alternatively, if whole-brain volume becomes abnormal shortly before the onset of symptoms-or even after symptoms have developed - this would suggest a neurodegenerative aetiology. Populationbased data suggest that head size is abnormal at birth among those who later develop schizophrenia, compared with controls (Ward et al, 1996; Harrison, 1999). Research in the offspring of people with schizophrenia, in people at high genetic risk of this disorder or in patients in its prodromal phase might help to address this aetiological question.

\section{When does volumetric change occur?}

Some brain structures in people with firstepisode schizophrenia appear to show a volumetric deficit that is significant at diagnosis and that is also progressive over the later course of illness. For example, the lateral ventricles are significantly larger than normal at diagnosis (Table 4) and ventricular volume tends to increase significantly in longitudinal studies. Volumetric deficits at diagnosis are seen in the hippocampus (Table 3), in cortical grey matter, in Heschl's gyrus, in the planum temporale and in temporal grey matter, and all of these structures also show continued volumetric loss over time (further information available from the author upon request). 
Table 4 Ventricular volume in cross-sectional studies

\begin{tabular}{|c|c|c|c|c|c|c|c|c|}
\hline \multirow[t]{3}{*}{ Reference' } & \multicolumn{6}{|c|}{ Ventricular volume, $\mathrm{mm}^{3}$} & \multirow{3}{*}{$\begin{array}{c}\text { Volume }^{2} \\
\%\end{array}$} & \multirow[t]{3}{*}{$P$} \\
\hline & \multicolumn{3}{|c|}{ Patient group } & \multicolumn{3}{|c|}{ Control group } & & \\
\hline & Mean & (s.d.) & $n$ & Mean & (s.d.) & $n$ & & \\
\hline \multicolumn{9}{|l|}{ Left lateral ventricle } \\
\hline Fannon et al (2000a) & 5.10 & $(3.00)$ & 14 & 4.50 & $(1.90)$ & 25 & 113.3 & NS \\
\hline Fannon et al (2000b) & 6.20 & $(3.20)$ & 37 & 4.50 & $(1.90)$ & 25 & 137.8 & $<0.05$ \\
\hline James et al (1999) & 9.66 & $(4.00)$ & 29 & 6.16 & $(2.30)$ & 20 & 156.8 & $<0.001$ \\
\hline Lawrie et al (1999) & 3.90 & $(2.50)$ & 20 & 3.80 & $(2.80)$ & 30 & 102.6 & NS \\
\hline Whitworth et al (1998) & 4.96 & $(2.97)$ & 41 & 2.81 & $(1.49)$ & 32 & 176.5 & $<0.001$ \\
\hline Barr et al (1997) & 9.16 & $(4.22)$ & 32 & 6.98 & $(2.90)$ & 42 & 131.2 & $<0.02$ \\
\hline DeLisi et al (1991) & 6.84 & $(2.10)$ & 30 & 5.54 & $(1.80)$ & 20 & 123.5 & $<0.04$ \\
\hline Chua et al (2003) & 6.00 & $(1.50)$ & 19 & 5.00 & $(2.00)$ & 29 & 120.0 & 0.02 \\
\hline Degreef et al (1992) & 8.91 & $(3.96)$ & 40 & 6.70 & $(2.14)$ & 25 & 133.0 & NS \\
\hline Meta-analysis & 6.86 & & 262 & 5.13 & & 248 & 133.7 & $<0.0001$ \\
\hline \multicolumn{9}{|l|}{ Right lateral ventricle } \\
\hline Fannon et al (2000a) & 4.60 & $(2.10)$ & 14 & 4.70 & $(1.90)$ & 25 & 97.9 & NS \\
\hline Fannon et al (2000b) & 5.80 & $(2.90)$ & 37 & 4.70 & $(1.90)$ & 25 & 123.4 & NS \\
\hline James et al (1999) & 8.12 & $(3.32)$ & 29 & 5.89 & $(2.28)$ & 20 & 137.9 & $<0.02$ \\
\hline Lawrie et al (1999) & 3.70 & $(2.60)$ & 20 & 3.50 & $(2.00)$ & 30 & 105.7 & NS \\
\hline Whitworth et al (1998) & 4.99 & $(2.95)$ & 41 & 3.11 & $(1.65)$ & 32 & 160.5 & $<0.01$ \\
\hline Barr et al (1997) & 8.22 & $(4.22)$ & 32 & 6.52 & $(2.69)$ & 42 & 126.1 & $<0.02$ \\
\hline DeLisi et al (1991) & 6.75 & $(2.90)$ & 30 & 5.60 & $(1.70)$ & 20 & 120.5 & NS \\
\hline Chua et al (2003) & 5.10 & $(1.70)$ & 19 & 4.40 & $(1.70)$ & 29 & 115.9 & NS \\
\hline Degreef et al (1992) & 8.15 & $(3.05)$ & 40 & 6.75 & $(2.10)$ & 25 & $|2| .0$ & NS \\
\hline Meta-analysis & 6.26 & & 262 & 5.02 & & 248 & 124.7 & $<0.0001$ \\
\hline \multicolumn{9}{|l|}{ Third ventricle } \\
\hline Cahn et al (2002a) & 0.85 & $(0.32)$ & 20 & 0.62 & $(0.36)$ & 20 & 137.1 & 0.05 \\
\hline Fannon et al (2000a) & 0.77 & $(0.20)$ & 14 & 0.68 & $(0.21)$ & 25 & 113.2 & NS \\
\hline Fannon et al (2000b) & 0.90 & $(0.40)$ & 37 & 0.70 & $(0.20)$ & 25 & 128.6 & $<0.05$ \\
\hline James et al (1999) & 2.08 & $(0.66)$ & 29 & 1.60 & $(0.35)$ & 20 & 130.0 & 0.006 \\
\hline Lawrie et al (1999) & 0.60 & $(0.40)$ & 20 & 0.40 & $(0.20)$ & 30 & 150.0 & 0.02 \\
\hline Lim et al (1996) & 0.34 & $(0.12)$ & 22 & 0.27 & $(0.13)$ & 51 & 125.9 & $<0.05$ \\
\hline DeLisi et al (1991) & 0.99 & $(0.40)$ & 22 & 0.91 & $(0.20)$ & 13 & 108.8 & NS \\
\hline Degreef et al (1992) & 1.33 & $(0.38)$ & 40 & 1.12 & $(0.32)$ & 25 & 118.8 & $<0.03$ \\
\hline Meta-analysis & 0.99 & & 204 & 0.79 & & 209 & 125.3 & $<0.0001$ \\
\hline
\end{tabular}

I. Cahn et al (2002a) and Lim et al (1996) are not included in this evaluation of lateral ventricles because they did not report left and right lateral ventricles separately.

2 . Volume expressed as a percentage of control ventricular volume.

Some brain tissues appear to show a volumetric deficit at diagnosis, but the deficit may not progress over time. For example, there are volumetric deficits in the thalamus at diagnosis, according to four studies, but no longitudinal change has yet been described. Similarly, volume deficits in the insula are significant at diagnosis, according to two studies, but no longitudinal change has been described. This may mean that volumetric changes in the thalamus and insula are indeed not progressive, or it may mean that there are simply too few longitudinal studies to identify a progressive volume loss that is actually present in these structures.

\section{Imaging difficulties}

There are a great many difficulties in measuring brain volumes of patients with schizophrenia by MRI. A major problem is that the volumetric loss in patients is no more than $4 \%$ per year (further information available upon request), which may be close to the limit of detection by MRI, given the precision of volumetric methods (Howard et al, 2003; MacFall et $a l, 2004)$. A longitudinal study of a volume phantom found that changes of up to $5 \%$ could be introduced by changes in scanner hardware or software (MacFall et al, 2004). Such 'machine drift' can have an impact on volume measurement, as shown by a study of intracranial content in $\mathbf{1 1 3}$ healthy elderly participants (MacFall et al, 2004). Although the intracranial content 
cannot change after the cranial sutures close (Pfefferbaum et al, 1994; Giedd et al, 1999), error in its measurement averaged $\pm 1.5 \%$ (MacFall et al, 2004). This error could be corrected but, in the absence of correction, would confound any longitudinal measurement of brain volume (MacFall et al, 2004). In studies that control for intracranial volume, imprecision or inaccuracy may not have a major impact, but poor precision or low accuracy in even a subset of volumetric studies would lead to a lack of consensus among the various studies.

Imprecision or inaccuracy in the measurement of brain volume can arise in many ways. Perhaps the most likely source of error is voxel misclassification during brain segmentation (Wang \& Doddrell, 2002). Voxels classified as one tissue type could, with a relatively minor change in tissue $T_{1}$ or $T_{2}$, be classified as another tissue type (Steen et al, 1997). A second major issue is the familiar partial volume problem; since several tissues can occur in a volume much smaller than a typical imaging voxel, this would introduce error into the volume estimate of any tissue type (Tofts et al, 1997; Ballester et al, 2000; Wang \& Doddrell, 2002), and could potentially change the proportional allocation of tissue to tissue type. A third problem is the inconspicuousness of tissue edges; this type of error is really another type of partial volume error that would primarily affect the estimate of grey matter volume, since this often has poorly defined edges with cerebrospinal fluid. Error in the measurement of grey matter volume would change the estimate of total brain volume, so controlling for brain volume would not necessarily eliminate 'machine drift' in a longitudinal study. A fourth issue is head tilt, or angulation of the imaging slab over the brain, since different volumes of brain may be interrogated in different imaging examinations. This problem can only be overcome by striving for full brain coverage during an examination. Finally, non-systematic errors (mistakes) can be made during the complex analytic process that is required for MRI volumetry (Haller et al, 1997). In short, because error can be substantial and because brain volumetric changes from normal in patients with first-episode schizophrenia appear to be quite small, some of the differences reported between patients and controls (Tables 2-4) are probably artefactual.

\section{Clinical difficulties}

A great many clinical difficulties complicate a volumetric search for the causes of schizophrenia. An enormous problem is that patients are typically treated with antipsychotic medications as soon as possible after diagnosis. Different patients may receive different medications at different dosages, and such treatment heterogeneity is almost impossible to eliminate. This makes it essential to determine whether there are acute effects of medication on total brain volume (DeLisi et al, 1991; Chakos et al, 1994; Gur et al, 1998). If brain volumetric changes in response to medication are rapid, then the length of time between first medication and imaging evaluation could be a major confounder. Antipsychotic medication has been postulated to have an effect on basal ganglia volume in as little as 6 months (Chakos et al, 1994), and it is possible that brain volumetric change in response to medication occurs even more rapidly. A further difficulty inherent to studying first-episode cases is that some patients may have been symptomatic, but undiagnosed, for a long time. If progressive brain volume changes are rapid in the period surrounding diagnosis, then the duration of undiagnosed illness would be a serious confounder. However, since no consistent relationship has been found between duration of illness and brain volume loss (Harrison et al, 2003), this may be less likely.

Recruiting patients with schizophrenia can be time-consuming, difficult and expensive, since many are unable or unwilling to comply with study requirements. Another problem is that brain structure may be weakly correlated with brain function, so that substantial variation in brain volume could be found in the absence of any variation in brain function (Uttal, 2001). These two problems together probably account for why so many studies of brain volume appear to be underpowered (Table 2). Many studies lack a sample size sufficient to test hypotheses that relate to what may be an inherently weak relationship, especially given the limitations of the methods (Haller et al, 1997; Howard et al, 2003; MacFall et al, 2004). To complicate the picture further, there may be genetic heterogeneity within the diagnosis, such that patients in a single study might actually have different diseases that converge in causing psychotic symptoms.

\section{Concluding remarks}

The most robust volumetric findings in patients with schizophrenia are those of grey matter volume loss (Table 3) and ventricular volume increase (Table 4), and these findings are probably linked. In monozygotic twins discordant for schizophrenia, there is a correlation between reduced left temporal grey matter volume and increased volume of cerebrospinal fluid in the left temporal horn, suggesting that loss of grey matter leads to an increase in ventricular volume (Suddath et al, 1989). Many more longitudinal studies of brain volume change in patients with first psychotic episodes are needed to determine which tissues are prone to the atrophy that manifests as ventricular volume increase.

This review confirms that grey matter deficits are present in patients with firstepisode psychosis (Hulshoff-Pol et al, 2001), whereas white matter changes have seldom been described (Sanfilipo et al, 2000; Hulshoff-Pol et al, 2004). Yet it is still not known whether changes in grey matter volume at first episode are associated with disease progression itself or with the many correlates of disease, including antipsychotic medication, alcoholism, drug misuse, malnutrition or even social deprivation. Both alcoholism (Joyce, 1996) and malnutrition (Swayze et al, 1996) are associated with acutely reversible changes in brain volume. Such volumetric changes are postulated to result from changes in brain water content, secondary to systemic hydration or serum protein content (Joyce, 1996; Swayze et al, 1996). Similar hydration mechanisms could be important in schizophrenia, since many patients suffer from malnutrition, dehydration and exposure (Shenton et al, 2001), so it is important to control for such environmental effects in studies.

It remains to be determined whether schizophrenia is a neurodegenerative process that begins at about the time of symptom onset and manifests as progressive volumetric loss thereafter, or whether it is better characterised as a neurodevelopmental process that results in abnormal brain volume beginning at an early age (Maynard et al, 2001).

\section{ACKNOWLEDGEMENTS}

R.G.S. is supported by the National Alliance for Research on Schizophrenia and Depression as a Hofmann Trust Investigator. Our research was also supported by MH61603 (J.A.L.), the University of 
North Carolina at Chapel Hill Schizophrenia Research Center, the National Institute of Mental Health Silvio Conte Center for the Neuroscience of Mental Disorders (MHI64065) and the Foundation of Hope.

\section{REFERENCES}

Antonova, E., Sharma, T., Morris, R., et al (2004)

The relationship between brain structure and neurocognition in schizophrenia: a selective review. Schizophrenia Research, 70, 117-145.

Bachmann, S., Pantel, J., Flender, A., et al (2003) Corpus callosum in first-episode patients with schizophrenia - a magnetic resonance imaging study. Psychological Medicine, 33, 1019-1027.

Ballester, M. A. G., Zisserman, A. \& Brady, M. (2000) Segmentation and measurement of brain structures in MRI including confidence bounds. Medical Image Analysis, 4, 189-200.

Barr, W. B., Ashtari, M., Bilder, R. M., et al (1997) Brain morphometric comparison of first-episode schizophrenia and temporal lobe epilepsy. British Journal of Psychiatry, 170, 515-519.

Bilder, R. M., Wu, H., Bogerts, B., et al (1994) Absence of regional hemispheric volume asymmetries in firstepisode schizophrenia. American Journal of Psychiatry, I5I, 1437-1447.

Bogerts, B., Ashtari, M., Degreef, G., et al (1990) Reduced temporal limbic structure volumes on magnetic resonance images in first episode schizophrenia. Psychiatry Research, 35, I-13.

Cahn, W., Hulshoff Pol, H. E., Bongers, M., et al (2002a) Brain morphology in antipsychotic-naïve schizophrenia: a study of multiple brain structures. British Journal of Psychiatry, I8I (suppl. 43), s66-s72.

Cahn, W., Hulshoff Pol, H. E., Lems, E. B., et al (2002b) Brain volume changes in first-episode schizophrenia: a I-year follow-up study. Archives of General Psychiatry, 59, 1002-1010.

Chakos, M. H., Lieberman, J. A., Bilder, R. M., et al (1994) Increase in caudate nuclei volumes of firstepisode schizophrenic patients taking antipsychotic drugs. American journal of Psychiatry, 15I, 1430-1436.

Chua, S. E., Lam, I.W., Tai, K. S., et al (2003) Brain morphological abnormality in schizophrenia is independent of country of origin. Acta Psychiatrica Scandinavica, 108, 269-275.

Copolov, D., Velakoulis, D., McGorry, P., et al (2000) Neurobiological findings in early phase schizophrenia. Brain Research Reviews, 31, 157-165.

Corson, P. W., Nopoulos, P., Andreasen, N. C., et al (1999) Caudate size in first-episode neuroleptic-naive schizophrenic patients measured using an artificial neural network. Biological Psychiatry, 46, 712-720.

Crespo-Facorro, B., Kim, J., Andreasen, N. C., et al (2000) Insular cortex abnormalities in schizophrenia: a structural magnetic resonance imaging study of firstepisode patients. Schizophrenia Research, 46, 35-43.

Davidson, L. L. \& Heinrichs, R.W. (2003)

Quantification of frontal and temporal lobe brainimaging findings in schizophrenia: a meta-analysis. Neuroimaging, 122, 69-87.

Degreef, G., Ashtari, M., Wu, H. W., et al (1991) Follow-up MRI study in first episode schizophrenia. Schizophrenia Research, 5, 204-206.

Degreef, G., Ashtari, M., Bogerts, B., et al (1992) Volumes of ventricular system subdivisions measured from magnetic resonance images in first-episode schizophrenic patients. Archives of General Psychiatry, 49 53I-537.

DeLisi, L. E., Hoff, A. L., Schwartz, J. E., et al (1991) Brain morphology in first-episode schizophrenic-like psychotic patients: a quantitative magnetic resonance imaging study. Biological Psychiatry, 29, 159-175.

DeLisi, L. E., Stritzke, P., Riordan, H., et al (1992) The timing of brain morphological changes in schizophrenia and their relationship to clinical outcome. Biological Psychiatry, 3I, 24I-254.

DeLisi, L. E., Hoff, A. L., Neale, C., et al (1994) Asymmetries in the superior temporal lobe in male and female first-episode schizophrenic patients: measures of the planum temporale and superior temporal gyrus by MRI. Schizophrenia Research, 12, 19-28.

DeLisi, L. E., Tew, W., Xie, S., et al (1995) A prospective follow-up study of brain morphology and cognition in first-episode schizophrenic patients: preliminary findings. Biological Psychiatry, 38, 349-360.

DeLisi, L. E., Sakuma, M., Tew, W., et al (1997) Schizophrenia as a chronic active brain process: a study of progressive brain structural change subsequent to the onset of schizophrenia. Psychiatry Research, 74, 129-140.

DeLisi, L. E., Sakuma, M., Ge, S., et al (1998) Association of brain structural change with the heterogeneous course of schizophrenia from early childhood through five years subsequent to a first hospitalization. Psychiatry Research, 84, 75-88.

Ettinger, U., Chitnis, X. A., Kumari, V., et al (200I) Magnetic resonance imaging of the thalamus in firstepisode psychosis. American Journal of Psychiatry, 158, 116-118.

Fannon, D., Tennakoon, L., O'Ceallaigh, S., et al (2000a) Third ventricle enlargement and developmental delay in first-episode psychosis: preliminary findings. British Journal of Psychiatry, 177, 354-359.

Fannon, D., Chitnis, X., Deku, V., et al (2000b) Features of structural brain abnormality detected in first-episode psychosis. American Journal of Psychiatry, I57, 1829-1834.

Giedd, J. N., Blumenthal, J., Jeffries, N. O., et al (1999) Brain development during childhood and adolescence: a longitudinal MRI study. Nature Neuroscience, 2, 861-863.

Gilbert, A. R., Rosenberg, D. R., Harenski, K., et al (200I) Thalamic volumes in patients with first-episode schizophrenia. American Journal of Psychiatry, $\mathbf{1 5 8}$ 618-624.

Gunduz, H., Wu, H., Ashtari, M., et al (2002) Basal ganglia volumes in first-episode schizophrenia and healthy comparison subjects. Biological Psychiatry, 5I, 80I-808

Gur, R. E., Cowell, P., Turetsky, B. I., et al (1998) A follow-up magnetic resonance imaging study of schizophrenia. Relationship of neuroanatomical changes to clinical and neurobehavioral measures. Archives of General Psychiatry, 55, 145-152.

Haller, J.W., Banerjee, A., Christensen, G. E., et al (1997) Three-dimensional hippocampal MR morphometry with high-dimensional transformation of a neuroanatomic atlas. Radiology, 202, 504-5I0.

Harrison, P. J. (1999) The neuropathology of schizophrenia: a critical review of the data and their interpretation. Brain, 122, 593-624.

Harrison, P. J., Freemantle, N. \& Geddes, J. R. (2003) Meta-analysis of brain weight in schizophrenia. Schizophrenia Research, 64, 25-34.

Hirayasu, Y., Sheton, M. E., Salisbury, D. F., et al (1998) Lower left temporal lobe MRI volumes in patients with first-episode schizophrenia compared with psychotic patients with first-episode affective disorder and normal subjects. American Journal of Psychiatry, I55, |384-139|.

Hirayasu, Y., Shenton, M. E., Salisbury, D. F., et al (1999) Subgenual cingulate cortex volume in firstepisode psychosis. American Journal of Psychiatry, 156 109|-1093.

Hirayasu, Y., Shenton, M. E., Salisbury, D. F., et al (2000a) Hippocampal and superior temporal gyrus volume in first-episode schizophrenia. Archives of General Psychiatry, 57, 618-619.

Hirayasu, Y., McCarley, R.W., Salisbury, D. F., et al (2000b) Planum temporale and Heschl gyrus volume reduction in schizophrenia: a magnetic resonance imaging study of first-episode patients. Archives of General Psychiatry, 57, 692-699.

Hirayasu, Y., Tanaka, S., Shenton, M. E., et al (200I) Prefrontal gray matter volume reduction in first episode schizophrenia. Cerebral Cortex, II, 374-38I.

Ho, B. C., Andreasen, N. C., Nopoulos, P., et al (2003) Progressive structural brain abnormalities and their relationship to clinical outcome: a longitudinal magnetic resonance imaging study early in schizophrenia. Archives of General Psychiatry, 60, 585-594.

Hoff, A. L., Neal, C., Kushner, M., et al (1994) Gender differences in corpus callosum size in firstepisode schizophrenics. Biological Psychiatry, 35, 913-919.

Howard, M. A., Roberts, N., Garcia-Finana, M., et al (2003) Volume estimation of pre-frontal cortical subfields using MRI and stereology. Brain Research. Brain Research Protocols, 10, 125-138.

Hulshoff-Pol, H. E., Schnack, H. G., Mandl, R. C., et al (200I) Focal gray matter density changes in schizophrenia. Archives of General Psychiatry, 58, III8-1125.

Hulshoff-Pol, H. E., Brans, R. G. H., van Haren, N. E. M., et al (2004) Gray and white matter volume abnormalities in monozygotic and same-gender dizygotic twins discordant for schizophrenia. Biological Psychiatry, 55, 126-130.

James, A. C., Crow, T. J., Renowden, S., et al (1999) is the course of brain development in schizophrenia delayed? Evidence from onsets in adolescence. Schizophrenia Research, 40, $1-10$

Joyal, C. C., Laakso, M. P., Tiihonen, J., et al (2002) A volumetric MRI study of the entorhinal cortex in first episode neuroleptic-naive schizophrenia. Biological Psychiatry, 5I, 1005-1007.

Joyal, C. C., Laakso, M. P., Tiihonen, J., et al (2003) The amygdala and schizophrenia: a volumetric magnetic resonance imaging study in first-episode, neurolepticnaive patients. Biological Psychiatry, 54, 1302-1304.

Joyce, E. M. (1996) Aetiology of alcoholic brain damage: alcoholic neurotoxicity or thiamine malnutrition? British Medical Bulletin, 50, 99-114.

Kasai, K., Iwanami, A., Yamasue, H., et al (2002) Neuroanatomy and neurophysiology in schizophrenia. Neuroscience Research, 43, 93-110.

Kasai, K., Shenton, M. E., Salisbury, D. F., et al (2003a) Differences and similarities in insular and temporal pole MRI gray matter volume abnormalities in first-episode schizophrenia and affective psychosis. Archives of General Psychiatry, 60, 1069-1077.

Kasai, K., Shenton, M. E., Salisbury, D. F., et a (2003b) Progressive decrease of left Heschl gyrus and planum temporale gray matter volume in first-episode schizophrenia: a longitudinal magnetic resonance imaging study. Archives of General Psychiatry, 60 766-775. 
Kasai, K., Shenton, M. E., Salisbury, D. F., et al (2003c) Progressive decrease of left superior temporal gyrus graymatter volume in patients with first-episode schizophrenia. American Journal of Psychiatry, 160, 156-164.

Keshavan, M. S., Rosenberg, D., Sweeney, J. A., et a (1998a) Decreased caudate volume in neuroleptic-naive psychotic patients. American Journal of Psychiatry, 155 774-778.

Keshavan, M. S., Rosenberg, D., Sweeney, J. A., et al (1998b) Superior temporal gyrus and the course of early schizophrenia: progressive, static, or reversible? Journal of Psychiatric Research, 32, 161-167.

Konick, L. C. \& Friedman, L. (200I) Meta-analysis of thalamic size in schizophrenia. Biological Psychiatry, 49, 28-38.

Laakso, M. P., Tiihonen, J., Syvalahti, E., et al (200I) A morphometric MRI study of the hippocampus in firstepisode, neuroleptic-naive schizophrenia. Schizophrenia Research, 50, 3-7.

Lang, D. J., Kopala, L. C., Vandorpe, R. A., et al (200I) An MRI study of basal ganglia volumes in firstepisode schizophrenia patients treated with risperidone. American Journal of Psychiatry, 158, 625-631.

Lawrie, S. M., Whalley, H., Kestelman, J. M., et al (1999) Magnetic resonance imaging of brain in people at high risk of developing schizophrenia. Lancet, 353, 30-33.

Lee, C. U., Shenton, M. E., Salisbury, D. F., et a (2002) Fusiform gyrus volume reduction in first-episode schizophrenia: a magnetic resonance imaging study Archives of General Psychiatry, 59, 775-781.

Lieberman, J. A., Alvir, J. M., Woerner, M., et a (1992) Prospective study of psychobiology in firstepisode schizophrenia at Hillside Hospital. Schizophrenia Bulletin, 18, 35I-37|.

Lieberman, J., Chakos, M., Wu, H., et al (200I) Longitudinal study of brain morphology in first episode schizophrenia. Biological Psychiatry, 49, 487-499.

Lim, K. O., Tew, W., Kushner, M., et al (1996) Cortical gray matter volume deficit in patients with first-episode schizophrenia. American Journal of Psychiatry, 153 1548-1553.

MacFall, J. R., Payne, M. E. \& Krishnan, K. R. R. (2004) MR scanner geometry changes: phantom measurements compared to intracranial contents calculations. Proceedings of the International Society for Magnetic Resonance in Medicine, II, 2182.

Matsumoto, H., Simmons, A., Williams, S., et al (200la) Structural magnetic imaging of the hippocampus in early onset schizophrenia. Biological Psychiatry, 49, 824-831.

Matsumoto, H., Simmons, A., Williams, S., et al (200lb) Superior temporal gyrus abnormalities in earlyonset schizophrenia: similarities and differences with adult-onset schizophrenia. American Journal of Psychiatry, 158, 1299-1304.

Maynard, T. M., Sikich, L., Lieberman, J. A., et a (200I) Neural development, cell-cell signaling, and the 'two-hit' hypothesis of schizophrenia. Schizophrenia Bulletin, 27, 457-476.

McCarley, R.W., Salisbury, D. F., Hirayasu, Y., et a (2002) Association between smaller left posterior superior temporal gyrus volume on magnetic resonance imaging and smaller left temporal P300 amplitude in first-episode schizophrenia. Archives of General Psychiatry, 59, 32I-331.

Nelson, M. D., Saykin, A. J., Flashman, L. A., et al (1998) Hippocampal volume reduction in schizophrenia as assessed by MRI: a meta-analytic study. Archives of General Psychiatry, 55, 433-440.

R. GRANT STEEN, PhD, COURTNEY MULL, MD, ROBERT McCLURE, MD, ROBERT M. HAMER, PhD, JEFFREY A. LIEBERMAN, MD, Department of Psychiatry, University of North Carolina at Chapel Hill, North Carolina, USA

Correspondence: Dr R. Grant Steen, Department of Psychiatry, University of North Carolina at Chapel Hill, Campus Box 7160, Chapel Hill, North Carolina 27599-7160,USA. Tel: + 919966 8382; e-mail: Grant_Steen@med.unc.edu

(First received 16 November 2004, final revision 12 July 2005, accepted 18 August 2005)

Niemann, K., Hammers, A., Coenen, V. A., et al (2000) Evidence of a smaller left hippocampus and left temporal horn in both patients with first episode schizophrenia and normal control subjects. Psychiatry Research, 99, 93-110.

Nopoulos, P., Torres, I., Flaum, M., et al (1995) Brain morphology in first-episode schizophrenia. American Journal of Psychiatry, 152, 1721-1723.

Okubo, Y., Tomoyuki, S. \& Oda, K. (200I) A review of MRI studies of progressive brain changes in schizophrenia. Journal of Medical and Dental Science, $\mathbf{4 8}$, 61-67.

Pfefferbaum, A., Mathalon, D. H., Sullivan, E. V., et al (1994) A quantitative magnetic resonance imaging study of changes in brain morphology from infancy to late adulthood. Archives of Neurology, 5I, 874-887.

Puri, B. K., Hutton, S. B., Saeed, N., et al (200I) A serial longitudinal quantitative MRI study of cerebral changes in first-episode schizophrenia using image segmentation and subvoxel registration. Psychiatry Research, 106, $14 \mid-150$

Razi, K., Greene, K. P., Sakuma, M., et al (1999) Reduction of the parahippocampal gyrus and the hippocampus in patients with chronic schizophrenia. British Journal of Psychiatry, 174, 512-519.

Salokangas, R. K. R., Cannon, T., Van Erp, T., et al (2002) Structural magnetic resonance imaging in patients with first-episode schizophrenia, psychotic and severe non-psychotic depression and healthy controls: results of the Schizophrenia and Affective Psychoses (SAP) project. British Journal of Psychiatry, I8I (suppl. 43), s58-65.

Sanfilipo, M., Lafargue, T., Rusinek, H., et al (2000) Volumetric measure of the frontal and temporal lobe regions in schizophrenia. Archives of General Psychiatry, 57, $47 \mid-480$

Shenton, M. E., Dickey, C. C., Frumin, M., et al (200I) A review of MRI findings in schizophrenia. Schizophrenia Research, 49, I-52.

Siever, L. J. \& Davis, K. L. (2004) The pathophysiology of schizophrenia disorders: perspectives from the spectrum. American Journal of Psychiatry, 161, 398-413.

Smith, G. N., Lang, D. J., Kopala, L. C., et al (2003) Developmental abnormalities of the hippocampus in first-episode schizophrenia. Biological Psychiatry, 53 555-561.

Steen, R. G., Ogg, R., Reddick, W. E., et al (1997) Agerelated changes in the pediatric brain: quantitative magnetic resonance imaging provides evidence of maturational changes during adolescence. American Journal of Neuroradiology, 18, 819-828.

Suddath, R. L., Casanova, M. F., Goldberg, T. E., et al (1989) Temporal lobe pathology in schizophrenia: quantitative magnetic resonance imaging study. American Journal of Psychiatry, 146, 464-472.

Sumich, A., Chitnis, X. A., Fannon, D. G., et al (2002) Temporal lobe abnormalities in first-episode psychosis. American Journal of Psychiatry, 159, 1232-1235.
Swayze, V. W., Anderson, A., Arndt, S., et al (1996) Reversibility of brain tissue loss in anorexia nervosa assessed with a computerized Talairach 3-D proportional grid. Psychological Medicine, 26 38I-390.

Szeszko, P. R., Bilder, R. M., Lenez, T., et al (1999) Investigation of frontal lobe subregions in first-episode schizophrenia. Psychiatry Research, 90, I-15.

Szeszko, P. R., Gunning-Dixon, F., Ashtari, M., et a (2003a) Reversed cerebellar asymmetry in men with first-episode schizophrenia. Biological Psychiatry, 53, 450-459.

Szeszko, P. R., Goldberg, E., Gunduz-Bruce, H., et al (2003b) Smaller anterior hippocampal formation volume in antipsychotic-naive patients with first-episode schizophrenia. American Journal of Psychiatry, 160 2190-2197.

Tofts, P. S., Barker, G. J., Filippi, M., et al (1997) An oblique cylinder contrast-adjusted (OCCA) phantom to measure the accuracy of MRI brain lesion volume estimation schemes in multiple sclerosis. Magnetic Resonance Imaging, 15, 183-192.

Torrey, E. F. (2002) Studies of individuals with schizophrenia never treated with antipsychotic medications: a review. Schizophrenia Research, 58, I0I-I5I.

Uttal, W. (200I) The New Phrenology: The Limits of Localizing Cognitive Processes in the Brain. Cambridge, MA: MIT Press.

Velakoulis, D., Pantelis, C., McGorry, P. D., et al (1999) Hippocampal volume in first-episode psychoses and chronic schizophrenia: a high-resolution magnetic resonance imaging study. Archives of General Psychiatry, 56, $133-14 \mid$.

Wang, D. \& Doddrell, D. M. (2002) MR image-based measurement of rates of change in volumes of brain structures. Part I: Method and validation. Magnetic Resonance Imaging, 20, 27-40.

Ward, K. E., Friedman, L., Wise, A., et al (1996) Metaanalysis of brain and cranial size in schizophrenia. Schizophrenia Research, 22, 197-213.

Whitworth, A. B., Honeder, M., Kremser, C., et al (1998) Hippocampal volume reduction in male schizophrenic patients. Schizophrenia Research, 31, 73-8I.

Wood, S. J., Velakoulis, D., Smith, D. J., et al (200I) A longitudinal study of hippocampal volume in first episode psychosis and chronic schizophrenia. Schizophrenia Research, 52, 37-46.

Wright, I. C., Rabe-Hesketh, S., Woodruff, P. W. R., et al (2000) Meta-analysis of regional brain volumes in schizophrenia. American Journal of Psychiatry, 157, 16-25.

Zipursky, R. B., Lambe, E. K., Kapur, S., et al (1998a) Cerebral gray matter volume deficits in first episode psychosis. Archives of General Psychiatry, 55 540-546.

Zipursky, R. B., Zhang-Wong, J., Lambe, E. K., et al (1998b) MRI correlates of treatment response in first episode psychosis. Schizophrenia Research, 30 $81-90$. 